\title{
Adsorption of Acid Orange 7 in Aqueous Solution by Biochar from Peanut Shell Supported with Clay Mineral Kaolinite
}

\author{
Keyuan Huang, Wangying Li, Yue Wang, Bin Liu, Ruolin Xu, Jing Dai, Xitong Zheng, Ningcan Yang, \\ Muqing Qiu and Li Han $\dagger$ \\ College of Life Science, Shaoxing University, Shaoxing, 312000, P.R. China \\ †Corresponding author: Li Han; 51778067@qq.com
}

Nat. Env. \& Poll. Tech.
Website: www.neptjournal.com
Received: $29-10-2019$
Revised: 18-11-2019
Accepted: 16-01-2020
Key Words:
Adsorption
Acid Orange 7
Kaolinite
Biochar

\begin{abstract}
Biochar was prepared from the peanut shell. Then, it was mixed with the clay mineral kaolinite and stirred under the magnetic stirrer. The biochar derived from peanut shell supported with clay mineral kaolinite (B@K) was obtained. Adsorption experiments of dye Acid Orange 7 by B@K were conducted. The characteristics of $\mathrm{B} @ \mathrm{~K}$ were determined by the elemental analyzer, specific surface area meter, scanning electron microscopy, transmission electron microscopy, Fourier transform infrared spectroscopy, X-ray photoelectron spectrometer and the model axis-HS. The experimental results showed that a large number of oxygen-containing functional groups appear on the surface of B@K, which is beneficial for binding dye ions. The adsorption process fits well with the pseudo-second-order kinetic model. It indicated that the adsorption process was both physical adsorption and chemical adsorption. Chemical adsorption is the main adsorption process. Langmuir isotherm model can better describe the adsorption isothermal process of $\mathrm{B} @ \mathrm{~K}$ on dye Acid Orange 7. The adsorption process is monolayer adsorption process.
\end{abstract}

\section{INTRODUCTION}

With the development of the printing and dyeing industry, a large number of dyes in China will be applied to many plants every year (Hu et al. 2017a). Therefore, it also produces a large amount of dye wastewater into the environment. The printing and dyeing wastewater is one of the most difficult to be treated among the industrial wastewaters at present. The printing and dyeing wastewater has large water volume, high organic matter content, complex composition, difficult to be degraded, and so on (Hu et al. 2017b, Qiu et al. 2018). Moreover, dye wastewater concentration in a water body usually remains low, which will cause the destruction of the water system for the decreasing of the water transmittance by the dye wastewater ( $\mathrm{Hu}$ et al. 2017c). Additionally, the products of dye wastewater degraded are mainly carcinogenic aromatic compounds. Effective treatment of this kind of wastewater will be very urgent (Rafatullah et al. 2010, Louis et al. 2018).

At present, the treatment methods of dye wastewater mainly include physico-chemical and biological methods (Hu et al. 2013). Among these methods, adsorption using activated carbon as an adsorbent is a commonly used treatment method for removing organic dyes in water. However, the high cost of activated carbon limits its application widely. Therefore, research on adsorbent containing lower costs and higher efficiency treatment is widely concerned by many researchers (Lu et al. 2012).

As a new type of efficient and inexpensive adsorbent, biochar is a better material. Biochar is a highly aromatized structure, and carboxyl group, phenolic hydroxyl group, carbonyl group and acid anhydride appear on the surface of biochar. Because of these structural characteristics, biochar is a good adsorption material. Raw materials for the preparation of biochar are very extensive (Kennedy et al. 2007, Wu 2007, Ling et al. 2011, Pardieu et al. 2016, Lefebvre et al. 2017). At present, the agricultural waste, the forestry waste and the industrial organic waste were applied into the preparation of biochar, and the biochar derived from these materials own good adsorption ability (Nautiyal et al. 2016, Khataee et al. 2018). Crop resources are abundant in China. Every year, a large amount of peanut shell was burned. It not only wastes of resources but also pollution of air. It is an urgent problem to develop clean and efficient technology and utilize these agricultural waste resources (Maria et al. 2018).

To improve the adsorption characteristics of biochar, it is usually modified by a clay mineral. In this study, the preparation of biochar from peanut shell supported with clay mineral kaolinite was explored. The biochar@kaolinite (B@K) was obtained. Then, the adsorption ability of B@K to remove dye Acid Orange 7 from aqueous solution was 


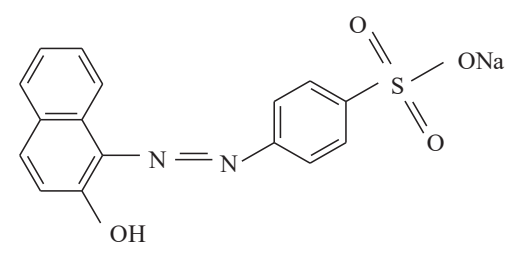

Fig. 1: The chemical structure of the dye Acid Orange 7.

tested. Additionally, the other goals of the study are: (1) study on the characteristics of B@K; (2) the adsorption kinetics and adsorption isotherms were discussed in details; (3) the adsorption mechanism was explored.

\section{MATERIALS AND METHODS}

Dyes and Chemicals: The dye Acid Orange 7 was chosen as an object in this experiment. It was purchased from Shanghai Chemical Co. Ltd. in China. Its molecular formula is $\mathrm{C}_{16} \mathrm{H}_{11} \mathrm{O}_{4} \mathrm{~N}_{2} \mathrm{SNa}$. The chemical structure of the dye Acid Orange 7 is shown in Fig. 1.

Preparation of B@K: The peanut shells were washed with deionized water, and dried at $80^{\circ} \mathrm{C}$ for $24 \mathrm{~h}$. The dried peanut shells were crushed and sieved into 80 meshes. $10 \mathrm{~g}$ of peanut shell powder was taken into a $200 \mathrm{~mL}$ reaction vessel containing $100 \mathrm{~mL}$ of distilled water and kept at $140^{\circ} \mathrm{C}$ for $24 \mathrm{~h}$. After cooling, 80 meshes of biochar powder derived from peanut shells was obtained. $5 \mathrm{~g}$ of biochar power and $5 \mathrm{~g}$ of clay kaolinite were added to the $200 \mathrm{~mL}$ of a beaker containing $100 \mathrm{~mL}$ distilled water and stirred for $30 \mathrm{~min}$ on a magnetic stirrer. Then, they were dried at $80^{\circ} \mathrm{C}$ for $24 \mathrm{~h}$ to obtain the biochar derived from peanut shells supported with clay mineral kaolinite (B@K).

Effect of contact time on the removal rate: $0.5 \mathrm{~g}$ of $\mathrm{B} @ \mathrm{~K}$ powder was added into a $250 \mathrm{~mL}$ Erlenmeyer flask containing $200 \mathrm{~mL}$ of $10 \mathrm{mg} / \mathrm{L}$ dye Acid Orange 7, and placed in an incubator at $25^{\circ} \mathrm{C}$ and $150 \mathrm{r} / \mathrm{min}$. The contact time was $5,10,20,40,60,90,120,180,240,360$ and $480 \mathrm{~min}$. The sample was taken from the supernatant, placed in a centrifuge tube and centrifuged at $8000 \mathrm{r} / \mathrm{min}$ for $5 \mathrm{~min}$. Then, it was measured with a UV-1600 spectrophotometer at $485 \mathrm{~nm}$.

Effect of the initial concentration of dye on the removal rate: $0.5 \mathrm{~g}$ of $\mathrm{B} @ \mathrm{~K}$ powder was added into a $250 \mathrm{~mL}$ Erlenmeyer flask containing $200 \mathrm{~mL}$ of dye Acid Orange 7, and placed in an incubator at $25^{\circ} \mathrm{C}$ and $150 \mathrm{r} / \mathrm{min}$. The contact time was $360 \mathrm{~min}$. The initial dye concentration ranged from 5 to $80 \mathrm{mg} / \mathrm{L}$. The sample was determined with a UV-1600 spectrophotometer at $485 \mathrm{~nm}$.

Analytical methods: The value of $\mathrm{pH}$ was measured with a $\mathrm{pH}$ probe according to APHA standard method. The concen- tration of dye Acid Orange 7 was measured with a UV-1600 spectrophotometer at $485 \mathrm{~nm}$.

The removal rate of dye Acid Orange 7 was calculated as follows:

$$
Q=\frac{C_{0}-C_{t}}{C_{0}} \times 100 \%
$$

Where, $\mathrm{C}_{0}$ and $\mathrm{C}_{\mathrm{t}}(\mathrm{mg} / \mathrm{L})$ are the initial and equilibrium concentrations of dye Acid Orange 7 in solution respectively. $\mathrm{Q}$ is the removal rate of dye Acid Orange 7. The elements of C, H, O and $\mathrm{N}$ were determined by Elemental Analyzer (Vario ELIII, Elementar, Germany). BET specific surface area was measured by the Specific Surface Area Meter (Autosorb-iQ3). The particle microstructure of B@K was determined by scanning electron microscopy (JEOL 6500F, Japan) and Transmission electron microscopy (JEM-F200, Japan) respectively. The functional groups on the surface of B@K were determined by Fourier transform infrared spectroscopy (Bruker Tensor 27). X-ray photoelectron spectrometer (Krato AXIS Ultra DLD, Japan) and the model Axis-HS (Kratos Analytical) were used to determine the surface composition.

The pseudo-first-order kinetic model and the pseudo-second-order kinetic models were applied in this study to elaborate the adsorption kinetics.

The pseudo-first-order rate is given as (Liu et al. 2016):

$$
\ln \left(q_{e}-q_{t}\right)=\ln q_{e}-k_{1} t
$$

The pseudo-second-order rate is given as:

$$
\frac{t}{q_{t}}=\frac{1}{k_{2} q_{e}^{2}}+\frac{1}{q_{e}} t
$$

Where, $\mathrm{q}_{\mathrm{e}}(\mathrm{mg} / \mathrm{g})$ is the amount of adsorbed solute at equilibrium conditions, $\mathrm{q}_{\mathrm{t}}(\mathrm{mg} / \mathrm{g})$ is the amount of adsorbed solute at any time $\mathrm{t}(\mathrm{min}), \mathrm{k}_{1}\left(\mathrm{~h}^{-1}\right)$ and $\mathrm{k}_{2}(\mathrm{~g} / \mathrm{mg} / \mathrm{h})$ are the model rate constants respectively.

The Langmuir model and Freundlich model were used in this experiment. The Langmuir model and Freundlich model of linear forms are (Ding et al. 2016):

$$
\begin{gathered}
\frac{\mathrm{C}_{\mathrm{e}}}{\mathrm{q}_{\mathrm{e}}}=\frac{1}{K_{L} q_{\max }}+\frac{C_{e}}{q_{\max }} \\
\ln q_{e}=\ln K_{F}+\frac{1}{n} \ln C_{e}
\end{gathered}
$$


Where, $\mathrm{C}_{\mathrm{e}}(\mathrm{mg} / \mathrm{L})$ is the equilibrium concentration in the solution, $\mathrm{q}_{\mathrm{e}}(\mathrm{mg} / \mathrm{g})$ is the adsorbate adsorbed at equilibrium, $\mathrm{q}_{\max }(\mathrm{mg} / \mathrm{g})$ is the maximum adsorption capacity, $\mathrm{n}$ is the Freundlich constant related to adsorption intensity, $\mathrm{K}_{\mathrm{L}}$ $(\mathrm{L} / \mathrm{mg})$ and $\mathrm{K}_{\mathrm{F}}\left((\mathrm{mg} / \mathrm{g})^{1 / \mathrm{n}}\right)$ are the adsorption constants for Langmuir and Freundlich models respectively.

Statistical analyses of data: All experiments were repeated in duplicate and the data of results were the mean and the standard deviation (SD). The value of the SD was calculated by Excel Software. All error estimates given in the text and error bars in figures are the standard deviation of means (mean $\pm \mathrm{SD}$ ). All statistical significance was noted at $\alpha=0.05$ unless otherwise stated.

\section{RESULTS AND DISCUSSION}

Characteristics of $\mathbf{B} @ \mathbf{K}$ : The elements C, H, O and N of $\mathrm{B} @ \mathrm{~K}$ are $44.21 \%, 4.18 \%, 47.16 \%$ and $4.45 \%$ respectively. BET specific surface area of B@K is $6.15 \mathrm{~m}^{2} / \mathrm{g}$. The images of SEM and TEM are shown in Fig. 2.
From Fig. 2, it can be concluded that it was a layered and irregular structure. The irregular surface of B@K is beneficial to adsorb.

Fig. 3 is the FT-IR spectrum of B@K. There is a strong adsorption peak in the range from $3000 \mathrm{~cm}^{-1}$ to $3700 \mathrm{~cm}^{-1}$, which may refer to the stretching vibration of a hydroxyl radical group. It indicates that a large number of oxygen-containing functional groups appear on the surface of B @ K, such as carboxyl groups, hydroxyl groups, carbonyl groups and so on. The peak at $1645 \mathrm{~cm}^{-1}$ may correspond to stretching vibration of a carboxyl group, or an ester group, or an aldehyde $\mathrm{C}=\mathrm{O}$ group. The peaks at $1400 \mathrm{~cm}^{-1}$ and $1060 \mathrm{~cm}^{-1}$ may correspond to the aromatic group and $\mathrm{C}-\mathrm{O}-\mathrm{C}$ group respectively. The peaks at $820 \mathrm{~cm}^{-1}, 562 \mathrm{~cm}^{-1}$ and $472 \mathrm{~cm}^{-1}$ may correspond to $\mathrm{C}-\mathrm{H}$ stretching functional group, -COObending vibration functional group and $\mathrm{S}_{\mathrm{i}}-\mathrm{O}-\mathrm{S}_{\mathrm{i}}$ functional group (Rebitanim et al. 2013).

The surface composition and chemical state of B@K were further investigated by XPS. The C1s XPS spectra of B@K are shown in Fig. 4. The C1s XPS spectra of B@K

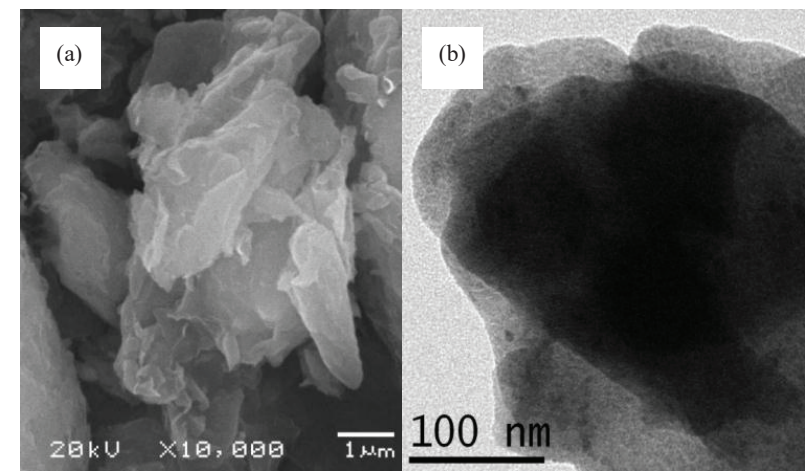

Fig. 2: SEM and TEM images of B @K, (a) SEM image, (b) TEM image.

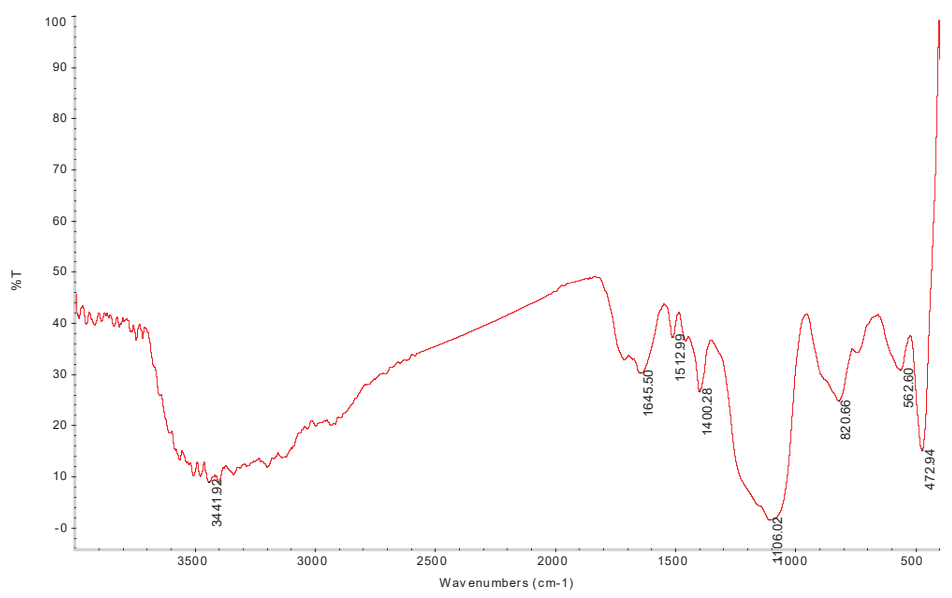

Fig. 3: FT-IR spectrum of B@K 
can be the major component with peaks at $284.4 \mathrm{eV}$, which may be assigned to $\mathrm{C} / \mathrm{N}-\mathrm{O}, \mathrm{C}-\mathrm{O}$ or $\mathrm{C}-\mathrm{C}$ bonds. These results suggest that $\mathrm{B} @ \mathrm{~K}$ possess considerable amounts of oxygen/ nitrogen containing groups on its surface, which is beneficial for binding dye ions (Mohamed et al. 2016).

Effect of contact time on the removal rate: Fig. 5 is the effect of contact time on the removal rate of dye Acid Orange 7.

As shown in Fig. 5, the adsorption process of dye Acid Orange 7 by B@K can be divided into three stages. At the first stage of $5 \mathrm{~min}$, the removal rate of dye Acid Orange 7 is very fast. It is because the concentration of dye Acid Orange 7 on the surface of the B@K is the highest in the initial stage. The removal rate increases the action of mass transfer. From 5 to 360 minutes, the removal rate is faster, and the removal rate tends to increase slowly with the increase of contact time. When the adsorption process begins, the difference in the concentration of dye between the surface of B@K and liquid gradually decreases, resulting in a gradual decrease in the removal rate. After $360 \mathrm{~min}$, the change of removal rate is very slow and the adsorption reaches an equilibrium state.

Effect of initial concentration on the removal rate: The effect of initial concentration of dye Acid Orange 7 on the removal rate is shown in Fig. 6. It can be seen that as the initial concentration of dye Acid Orange 7 increases, the amount of adsorption also gradually increases. This is mainly due to an increase in the difference in the initial concentration of dye Acid Orange 7.

Sorption kinetics: According to the data from Fig. 3, Eqn. 2 and Eqn. 3, parameters of the pseudo-first-order kinetic model and the pseudo-second-order kinetic model for the description of dye Acid Orange 7 adsorption onto B@K were calculated. They are given in Table 1 .

From Table 1, it can be seen that the adsorption process fits well with the pseudo-second-order kinetics model according to the value of $\mathrm{R}^{2}(0.9973>0.8622)$. It also indicates that the adsorption process is both physical adsorption and

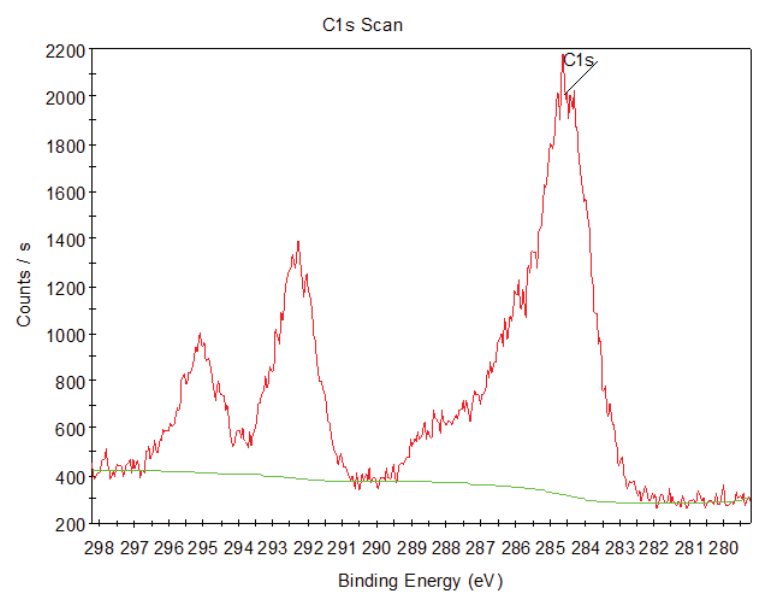

Fig. 4: XPS spectrum of B@K.

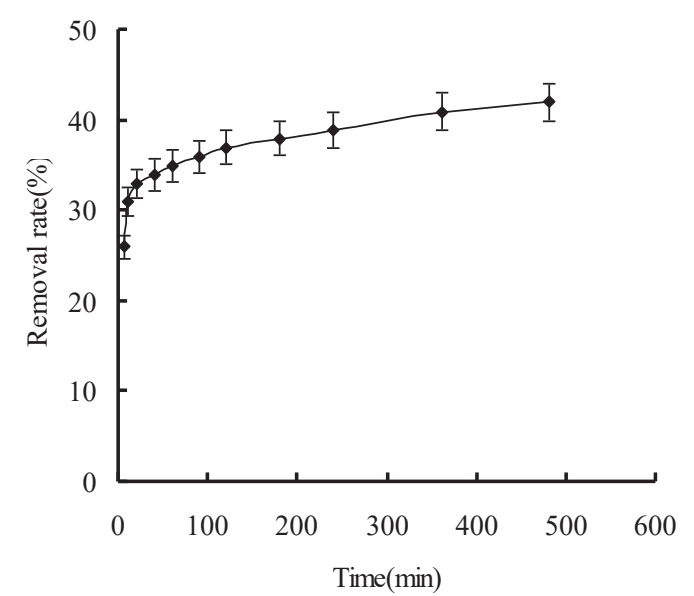

Fig. 5: Effect of contact time on the removal rate of dye Acid Orange 7 by B@K. 


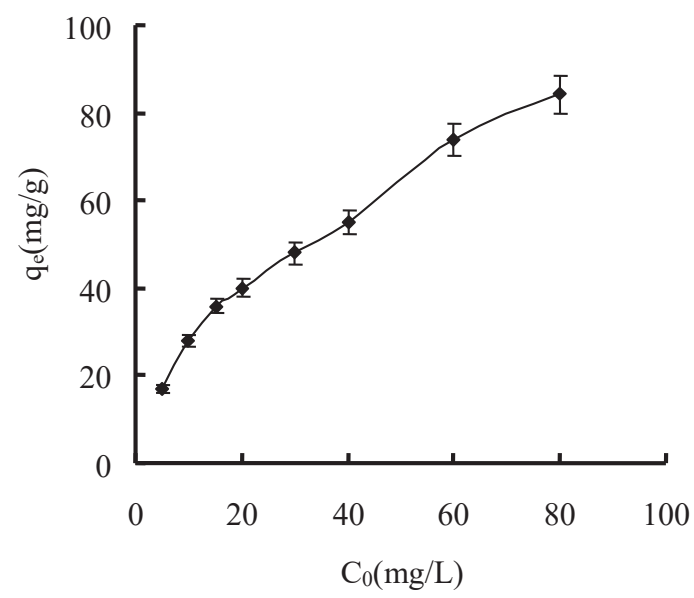

Fig. 6: Effect of the initial concentration of dye Acid Orange 7 on the removal rate by B@K.

chemical adsorption. Chemical adsorption is the main adsorption process.

Sorption isotherms: According to the data from Fig. 4, Eqn. 4 and Eqn. 5, parameters of Langmuir isotherm model and Freundlich isotherm model for the description of dye Acid Orange 7 adsorption onto B @ K are given in Table 2.

From Table 2, the Langmuir isotherm model can better describe the adsorption isothermal process of $\mathrm{B} @ \mathrm{~K}$ on dye Acid Orange 7 according to the value of $\mathrm{R}^{2}(0.9836>0.9623)$. The adsorption process is monolayer adsorption process. As the initial concentration of dye increases, the amount of adsorption increases and gradually reaches equilibrium.

\section{CONCLUSIONS}

(1) B@K was a layered and irregular structure. A large number of oxygen-containing functional groups appeared on the surface of $\mathrm{B} @ \mathrm{~K}$, which is beneficial for binding dye ions.

(2) The adsorption process fits well with the pseudo-secondorder kinetics model. It indicates that the adsorption process is both physical adsorption and chemical adsorption. Chemical adsorption is the main adsorption process.

(3) Langmuir isotherm model can better describe the adsorption isothermal process of B@K on dye Acid Orange 7. The adsorption process is monolayer adsorption process. As the initial concentration of dye increases, the amount of adsorption increases and gradually reaches equilibrium.

\section{ACKNOWLEDGEMENTS}

This work is supported by the financial support from the research fund program of national Nature Science Foundation of China (No. 21876115).

Table 1: Parameters of the pseudo-first-order kinetic model and the pseudo-second-order kinetic model for the description of dye Acid Orange 7 adsorption onto B@K.

\begin{tabular}{|llllll|}
\hline \multicolumn{2}{|l|}{ pseudo-first-order kinetic model } & \multicolumn{2}{l|}{ pseudo-second-order kinetic model } \\
\hline $\begin{array}{l}\mathrm{k}_{1} \\
(\mathrm{~min})\end{array}$ & $\begin{array}{l}\mathrm{q}_{\mathrm{e}} \\
(\mathrm{mg} / \mathrm{g})\end{array}$ & $\mathrm{R}^{2}$ & $\begin{array}{l}\mathrm{k}_{2} \\
(\mathrm{mg} / \mathrm{g} \cdot \mathrm{min})\end{array}$ & $\begin{array}{l}\mathrm{q}_{\mathrm{e}} \\
(\mathrm{mg} / \mathrm{g})\end{array}$ \\
\hline 0.4815 & 13.18 & 0.8622 & 0.00292 & 15.46 \\
\hline
\end{tabular}

Table 2: Parameters of the Langmuir isotherm model and Freundlich isotherm model for the description of dye Acid Orange 7 adsorption onto B @ K.

\begin{tabular}{|llllll|}
\hline Langmuir & \multicolumn{5}{c|}{ Freundlich } \\
\hline $\mathrm{q}_{\mathrm{m}}(\mathrm{mg} / \mathrm{g})$ & $\mathrm{K}_{\mathrm{L}}$ & $\mathrm{R}^{2}$ & $\mathrm{~K}_{\mathrm{F}}$ & $\mathrm{n}$ & $\mathrm{R}^{2}$ \\
\hline 101.28 & 0.0645 & 0.9836 & 11.3265 & 2.1786 & 0.9623 \\
\hline
\end{tabular}




\section{REFERENCES}

Ding, G.Y., Wang, B.Y., Chen, L.Y. and Zhao, S.J. 2016. Simultaneous adsorption of methyl red and methylene blue onto biochar and an equilibrium modeling at high concentration. Chemosphere, 163: 283-289.

Hu, B.W., Chen, G.H., Jin, C.G., Hu, J., Huang, C.C., Sheng, J., Sheng, G.D., Ma, J.Y. and Huang, Y.Y. 2017a. Macroscopic and spectroscopic studies of the enhanced scavenging of $\mathrm{Cr}(\mathrm{VI})$ and $\mathrm{Se}(\mathrm{VI})$ from water by titanate nanotube anchored nanoscale zero-valent iron. J. Hazard. Mater., 336: 214-221.

Hu, B.W., Hu, Q.Y., Xu, D. and Chen, C.G. 2017b. The adsorption of $\mathrm{U}(\mathrm{VI})$ on carbonaceous nanofibers: A combined batch, EXAFS and modeling techniques. Sep. Pur. Tech., 175: 140-146.

Hu, B.W., Qiu, M.Q., Hu, Q.Y., Sun, Y.B., Sheng G.D., Hu, J. and Ma, J.Y. 2017c. Decontamination of $\mathrm{Sr}$ (II) on magnetic polyaniline/graphene oxide composites: Evidence from experimental, spectroscopic, and modeling investigation. ACS Sustain. Chem. Eng., 5: 6924-6931.

Hu, L.X., Yang, F., Lu, W.C., Hao, Y. and Yuan, H. 2013. Heterogeneous activation of oxone with CoMg/SBA-15 for the degradation of dye Rhodamine B in aqueous solution. Appl. Catal. B Environ., 134: 7-18.

Kennedy, L.J., Vijaya, J.J., Sekaran, G. and Kayalvizhi, K. 2007. Equilibrium, kinetic and thermodynamic studies on the adsorption of m-cresol onto micro- and mesoporous carbon. J. Hazard. Mater., 149: 134-143.

Khataee, A., Gholami, P., Kalderis, D., Pachatouridou, E. and Konsolakis, M. 2018. Preparation of novel $\mathrm{CeO}_{2}$-biochar nanocomposite for sonocatalytic degradation of a textile dye. Ultrason. Sonochem., 41: 503-513

Lefebvre, L., Kelber, J., Jierry, L., Ritleng, V. and Edouard, D. 2017. Polydopamine-coated open cell polyurethane foam as an efficient and easy-to-regenerate soft structured catalytic support $\left(\mathrm{S}_{2} \mathrm{CS}\right)$ for the reduction of dye. J. Environ. Chem. Eng., 5: 79-85.

Ling, S.K., Tian, H.Y., Wang, S.B., Rufford, T., Zhu, Z.H. and Buckley, C.E. 2011. KOH catalysed preparation of activated carbon aerogels for dye adsorption. J. Colloid Interf. Sci., 357: 157-162.

Liu, Na, Zhu, M.L., Wang, H. and Ma, H.Q. 2016. Adsorption charac- teristics of Direct Red 23 from aqueous solution by biochar. J. Mol. Liq., 223: 335-342.

Louis, L., Géraldine, A., Alissa, B. and David, E. 2018. Adsorption of dye with carbon media supported on polyurethane open cell foam. Catal. Today, 301: 98-103.

Lu, J., Lin, J.X., Zhao, X.L. and Cao, R. 2012. Photochromic hybrid materials of cucurbituril and polyoxometalates as photocatalysts under visible light. Chem. Commun., 48: 669-671.

Maria, A.Z., Marcelo, G., Daniele, P., Edson, L.F., Gabriela, C.C. and Guilherme L.D. 2018. New biochar from pecan nutshells as an alternative adsorbent for removing reactive red 141 from aqueous solutions. J. Clean. Prod., 171: 57-65.

Mohamed, E.M., Gehan, M.N., Nabila, M.E., Heba, I.B., Sandeep, K. and Tarek, M.A. 2016. Kinetics, isotherm, and thermodynamic studies of the adsorption of reactive red 195 A dye from water by modified Switchgrass Biochar adsorbent. J. Indus. Eng. Chem., 37: 156-167.

Nautiyal, P., Subramanian, K.A. and Dastidar, M.G. 2016. Adsorptive removal of dye using biochar derived from residual algae after in-situ transesterification: Alternate use of waste of biodiesel industry. J. Environ. Manage., 182: 187-197.

Pardieu, E., Chau, N.T.T., Dintzer, T., Romero, T., Favier, D., Roland, T., Edouard, D., Jierry, L. and Ritleng, V. 2016. Polydopamine-coated open cell polyurethane foams as an inexpensive, flexible yet robust catalyst support: a proof of concept. Chem. Commun., 52: 4691-4693.

Qiu, M.Q., Wang, M., Zhao, Q.Z., Hu, B.W. and Zhu, Y.L. 2018. XANES and EXAFS investigation of uranium incorporation on nZVI in the presence of phosphate. Chemosphere, 201: 764-771.

Rafatullah, M., Sulaiman, O., Hashim, R. and Ahmad, A. 2010. Adsorption of methylene blue on low-cost adsorbents: A review. J. Hazard. Mater., 177: 70-80.

Rebitanim, N.Z., Azlina, W.A., Ghani, K., Rebitanim, N.A. and Salleh, M.A.M. 2013. Potential applications of wastes from energy generation particularly biochar in Malaysia. Renew. Sus. Energ. Rev., 21: 694-702.

Wu, C. 2007. Adsorption of reactive dye onto carbon nanotubes: Equilibrium, kinetics and thermodynamics. J. Hazard. Mater., 144: 93-100. 